\title{
Does Negotiating with Terrorists Make Them More Risk Seeking?
}

\author{
Peter J Phillips ${ }^{1} \&$ Gabriela Pohl ${ }^{2}$ \\ ${ }^{1}$ School of Accounting, Economics and Finance, University of Southern Queensland, Toowoomba, Queensland, \\ Australia \\ ${ }^{2}$ Gabriela Pohl, School of Humanities and Communication, University of Southern Queensland, Toowoomba, \\ Queensland \\ Correspondence: Peter J Phillips, School of Accounting, Economics and Finance, University of Southern \\ Queensland, Toowoomba, Queensland 4350, Australia. Tel: 617-4631-5490.Email: phillips@usq.edu.au
}

Received: August 6, 2013 Accepted: August 30, 2013 Online Published: November 29, 2013

doi:10.5539/jpl.v6n4p108 URL: http://dx.doi.org/10.5539/jpl.v6n4p108

\begin{abstract}
We treat government concessions as additions to an expected payoffs schedule rather than as being synonymous with it. Government concessions that add to terrorists' expected payoffs past some point on a positively sloped risk-reward trade-off schedule will not make all terrorists more risk seeking. Such concessions do not represent certain 'windfall gains' to terrorists of the kind that interact with relative and absolute risk aversion. Although the expected payoffs to higher risk actions may be augmented by the government's concessions, terrorists must still bear risk in order to attain them. Terrorist groups that were unwilling to bear that risk before will not be enticed to bear it after expected payoffs are enhanced. Conversely, negative concessions or penalties will make terrorists more averse to risk because penalties alter the risk-reward trade-off in ways that make lower-risk actions more desirable to risk-averse terrorists. Our paper also explores the risk-reward characteristics of new and innovative terrorist actions relative to the structure of an existing expected payoffs schedule.
\end{abstract}

Keywords: terrorism, government policy, concessions, penalties, risk, innovation, Red Army Faction, $2^{\text {nd }}$ of June Movement

\section{Introduction}

In a grainy black and white photograph taken in early 1975, a weary man stares obediently into the camera. The sign he is holding says in block capital lettering, "PETER LORENZ - GEFANGENER DER BEWEGUNG 2. JUNI." (Note 1) Peter Lorenz was a German politician and mayoral candidate for West Berlin. He was kidnapped by the $2^{\text {nd }}$ of June Movement a few days before the mayoral elections in February 1975. After five days, the German government agreed to grant several concessions to the terrorists on the condition that Lorenz be released unharmed. These concessions included the release of 5 prisoners, transport to Yemen, about 100,000 Deutschmark in cash and media coverage of the departing 707 from Frankfurt airport (Winkler, 2008, p.246). Upon receipt of these concessions, Lorenz was released. The conventional wisdom that terrorists should never be negotiated with was disregarded. It would, however, be reinstated in just a matter of weeks as the German government confronted another set of terrorist demands, this time from the Red Army Faction (RAF) who were holding twelve hostages in the German embassy in Stockholm.

Members of the RAF stormed the embassy building in Stockholm in April 1975. Twelve hostages were seized. Explosives were laid in the building. The terrorists demanded the release of 26 prisoners, a 707 aircraft waiting at Frankfurt airport for departure, 520,000 Deutschmark and live television coverage in Sweden and Germany. This time, the German government voted in favour of a 'no concessions' policy on the grounds that the RAF terrorists were in a compromised position, the demands from the terrorists were too heavy and that further concessions to terrorists would not reflect favourably on the government. What must have been of some concern is the possibility that concessions granted to the 2nd of June Movement during the Lorenz kidnapping might have encouraged the RAF to undertake their own actions. The idea that a terrorist group can force the release of political prisoners was 'in the air' to such a degree that it was incorporated by well-known filmmaker Werner Fassbinder into a film he was making at the time of the Lorenz kidnapping (Winkler 2008, p.248). The timing of the Lorenz kidnapping and the Stockholm embassy incident could certainly be expected to have reinforced the 
conventional wisdom that concessions make terrorists more likely to engage in terrorist activity and, perhaps, to engage in riskier acts of terrorism.

The optimality of the 'never negotiate' policy was subjected to theoretical scrutiny by Lapan and Sandler (1988) but the analysis did not treat risk preferences explicitly. It is not uncommon for analytical work to leave risk preferences implicit and where risk preferences have been incorporated into the analysis, it has been usual to specify a particular type or level of risk preference, hold that specification constant, and explore the impact of government concessions in a comparative statics framework. Sandler, Tschirhart and Cauley's (1983) analysis is an example (Note 2). These economic studies focus on hostage-taking or kidnapping scenarios where terrorists attempt to bargain with the government in order to extract concessions. The examples with which we opened the paper are typical. Risk preferences have been treated in a similar manner in the international relations literature where the focus has been on inter-group or international conflict. Risk preferences are specified and the solution, if any, to the bargaining problem is determined within the boundaries of that specification. An example is Powell's (2002) analysis which represents an assessment of Rubinstein's (1982) 'standard model' under conditions of risk neutrality. Powell's analysis applies to scenarios where a 'bargaining surplus' may be divided in different proportions between the 'players'.

Analytical solutions to a number of the problems that are explored in this and related literature are often more easily attainable when risk preferences are left to one side or where risk neutrality is assumed. This leaves open the possibility for obtaining additional results by exploring what happens when risk preferences are specified in different ways. Skaperdas (2006) operates first under the assumption of risk neutrality before exploring the implications of risk aversion. Related concepts that emerged with the publication and dissemination of Kahneman and Tversky's $(1979 ; 1992)$ presentation of prospect theory, especially their concept of loss aversion, have been inserted into bargaining theory. Butler (2007) is representative of modern studies that explore the implications of different psychological and strategic aspects of bargaining, including different treatments of risk preferences, in scenarios previously explored with less nuanced specifications of attitudes towards the risk and potential losses and potential gains. Butler (2007), for example, finds important qualifications to the types of conclusions that might be reached by approaching bargaining problems from an expected value maximisation perspective - Fearon's (1995) model, for instance — rather than a prospect theoretical perspective (Note 3).

We are focused on the following problem. Can government concessions or penalties shape terrorists' preferences for risk? (Note 4) The setting for this problem is broader than the bargaining scenarios analysed in the papers listed above. The setting is a terrorism context where there are expected payoffs to terrorist actions, which include assassination, hijacking, bombing, hostage-taking and armed assaults. What these expected payoffs may be is still a matter for debate but they may include some or all of the following: the infliction of fatalities, the garnering of media coverage, the fostering of grassroots support, the formation of strategic links with other like-minded terrorist groups and so on (Abrahms 2006; 2008; 2011). We do not treat the concessions-ransoms, release of prisoners, changes of government policy and so forth - that might come from the government in response to an act of terrorism as the payoffs to terrorism. Rather, the government's concessions or penalties schedule adds to or alters but does not replace an underlying expected payoffs schedule that is characterised by a particular trade-off between risk and reward.

The paper attempts to bring terrorism researchers' attention to theoretical advances in parts of the economics literature that might otherwise go unnoticed. The distinguishing feature of the paper is its treatment of risk preferences as being shaped by the government's decisions regarding concessions and penalties rather than, as has been traditional, exploring the impact of different decisions under different specifications of terrorists' preferences for risk. We avoid treating concessions as being the payoff to the terrorism because Ross (2004, p. 216) has shown that replacing an entire incentives or payoffs schedule with a compensation or concessions schedule leads to theoretical results that are difficult to interpret in real-world settings. To clearly distinguish between total expected payoffs and concessions that represent additions or alterations to those payoffs, the theoretical apparatus that we apply to the analysis of the effect of government concessions and penalties on terrorists' risk preferences sets the expected payoffs schedule and concessions schedule side-by-side such that the effect of concessions on expected payoffs is clearly delineated. Terrorists' choices of actions on the basis of the risks and rewards reflected in the expected payoffs schedule can then be examined to determine whether the alteration of the risk-reward trade-off inherent in the expected payoffs schedule can be expected to influence terrorists' decisions regarding the amount of risk they are willing to bear. 


\section{The Shape of Payoffs, Concessions and Penalties}

Terrorists confront an expected payoffs schedule characterised by some, presumably positive, trade-off between risk and reward. Powell (2002) utilises a purely theoretical risk-reward trade-off. Phillips (2009) treats inflicted human tragedy measured by injuries and fatalities as the payoff to terrorism and sees a positive trade-off between risk and reward emerging empirically from the RAND-MIPT data as a concave set in expected-payoff-risk space. In dealing with bargaining scenarios it is easy to confuse a total payoffs schedule with the government's concessions schedule. The two will only be synonymous if concessions are the only relevant payoffs to a terrorist action. Usually, though, there will be some payoffs that lie outside of the government's control or its policy-making regimes. As mentioned in the introduction, these could be one or a combination of many different factors and some of them might be intangible or psychic in nature. A government's concessions schedule may alter or add to the existing expected payoffs schedule but it is not synonymous with it and does not replace it.

A payoffs schedule that incorporates all of the payoffs to terrorism, assuming they can all be measured (Note 5), would be multi-dimensional. We can imagine, however, that the payoffs schedule will be positively inclined in risk-reward space in order to encompass the positive trade-off between risk and reward that confronts terrorists. As Phillips (2009) has shown, different types of terrorist actions can be combined. When risk is measured by standard deviation or variance and the payoffs to each type of action are imperfectly correlated, a positively inclined and concave payoffs schedule emerges in risk-reward space. It is positively inclined because terrorist actions with a higher average payoff are attended by a higher risk or variance of their outcomes. It is concave because imperfect correlation between the payoffs to the different types of terrorism-payoffs to different actions do not move perfectly together over time - introduces concavity as an important aspect of the statistical structure. Only perfectly correlated payoffs across terrorist actions will produce a linear risk-reward trade-off. This concave trade-off between risk and reward that emerges when average payoffs and variance are considered in a context where terrorist actions can be combined is the clearest picture available of the type of statistical properties that may characterise the terrorists' total or overall payoffs schedule.

We could examine a basic but unrealistic situation where a government's 'schedule of concessions' replaces or becomes synonymous with the total payoffs schedule. However, unless we are willing to assume that concessions from the government are the only payoffs to terrorism this approach would lead us into the difficulties identified by Ross (2004, p.216). Even if we could make such an assumption the resulting analysis would, at best, apply only to a very small number of terrorist actions. The problem of government concessions in a terrorism context must be approached by treating the government's concessions schedule as something that alters or adds to the payoffs schedule but does not replace it. If the payoffs schedule is characterised by a particular trade-off between risk and reward an alteration of or addition to the payoffs schedule may change this risk-reward trade-off. It is possible that the alteration or addition could increase the payoffs to risky terrorist actions. However, this is different from making those riskier actions more desirable from a terrorist's point of view. Only if the concessions schedule alters the terrorists' risk preferences in a manner that makes them more risk seeking will riskier actions - even those attended by higher payoffs than before - be desired by terrorists.

If a payoffs schedule to terrorism might be conceived of as depicting a trade-off between risk and reward that is positively inclined and probably concave, the concessions and penalties that might be expected to characterise the government's strategy or policy towards terrorists must also be shaped in some way. The 'shape' of the government's concessions schedule is important. Recent work in other parts of economics, especially the analyses prepared by Carpenter (2000) and Ross (2004), has focused on the convexity and concavity of 'incentives schedules'. The problem addressed in the literature that encompasses agency theory and theoretical finance theory or financial economics is analogous to ours. Their problem is to alter or add to a total remuneration schedule with an incentives schedule in order to entice the individual being remunerated to take more or less risk. The language used in this contemporary literature speaks of convexifying or concavifying a utility function. A schedule that convexifies a utility function makes the individual more risk seeking. A schedule that concavifies a utility function makes the individual more averse to risk. The 'folklore', as Ross (2004) calls it, in financial economics and agency theory had been that a convex schedule convexifies a utility function while a concave schedule concavifies it. The shape, convex or concave, of the government's concessions schedule is central to our problem.

A convex schedule of concessions is one that will magnify the payoffs to terrorism past some point. The reason why this might be thought to decrease terrorists' aversion to risk and make them more risk seeking is that the effect of such a concession is to 'steepen' past some level of risk the positively inclined risk-reward trade-off characterising the expected payoffs schedule. Past some point of either payoff or risk, depending on how one 
looks at it, payoffs are higher than they were before. The problem with this intuition is that although the government's concessions have increased the payoffs to risky terrorist actions this is not the same thing as making these risky terrorist actions more desirable. Ross (2004) makes this point. This point will be the focus of discussion in the next section. For now, let us explore the shape of a concession from the government that magnifies payoffs past some point. Imagine that terrorists become aware or perceive that the government will grant positive and increasing concessions when the terrorists successfully execute a terrorist action which has a relatively high expected payoff and risk vis-à-vis other feasible terrorist actions. Now if terrorists embark on a more risky course of action associated with a relatively high expected payoff, they face a payoffs schedule that has been altered beyond this expected payoff by the government's concessions schedule. The alteration or addition that we explore first is a steepening of the risk-reward trade-off past some point such that higher risk actions have a higher payoff. Such a concession must be convex. The concession itself has an expected value and it is usual in the financial economics literature to depict such schedules geometrically in payoff-value space.

The simplest and most obvious way in which a government's concessions may alter the terrorist's payoff schedule is by adding to it. A convex schedule of concessions that magnifies the expected payoffs to terrorism past some point is a 'positive addition'. We shall consider 'negative additions' or penalties in a subsequent example. A convex schedule of concessions that when added to the payoffs schedule magnifies the payoffs past some point is depicted in Figure 1. There is nothing about the 'linear' schedule presented here that holds special theoretical or technical meaning. The slope of the schedule past the point where it is kinked could be either steeper or flatter than shown and the linear segments could be replaced with curved segments. The most important properties of the schedule are its positive expected valuedness and its convexity.

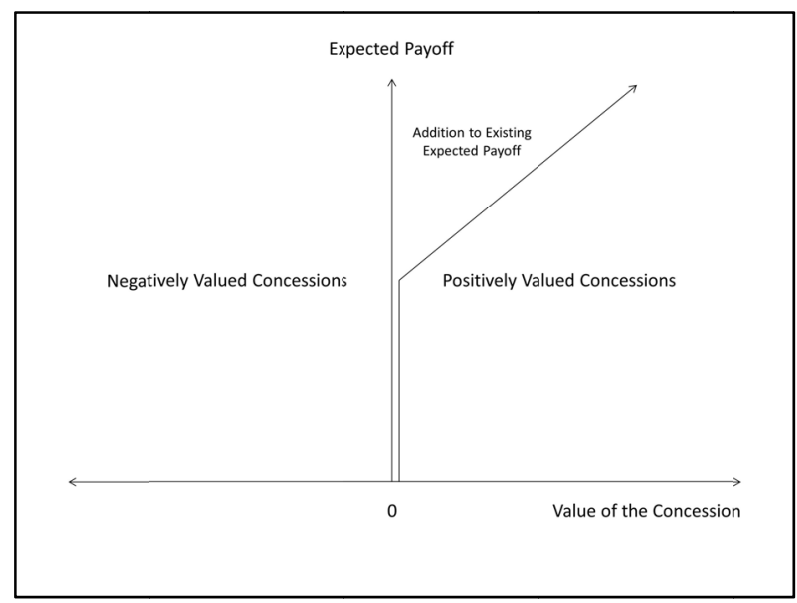

Figure 1. Convex concessions schedule

Figure 1 depicts a government concessions schedule that has a positive value past some point of the terrorist's expected payoff. At this point, the concessions schedule 'kinks' and becomes positively valued and increasingly positively valued as expected payoffs increase. The positive value of the concession is an addition to the terrorist's payoffs past this point. Up until the concessions schedule 'kinks' it coincides with the vertical axis and has zero value. This first segment of the concessions schedule has been drawn slightly to the right of the vertical axis but should be interpreted as coinciding with it. A concessions schedule like this one is related to the amount of risk that the terrorist takes. If there is a positive risk-reward trade-off characterising the existing payoffs to terrorism, the terrorist takes more risk to obtain higher expected payoffs. Actions that have a higher expected payoff may be those that are also most undesirable from the perspective of the citizenry upon whom the terroristic violence is inflicted. Higher risk-higher payoff attacks may have more expected fatalities or more hostages or more hostages of a certain type (for example, children) and so forth. As such, a government may be forced - or be perceived to be able to be forced - to provide concessions to either alleviate a crisis such as a hostage-taking scenario or to avoid a threatened repeat of the violence. Under these circumstances, the more risk the terrorist takes the more payoff he can expect and the more concessions he can expect to obtain from the government. The expected payoffs are risky and the outcomes are attended by variability. As such, it is not certain that a terrorist action will achieve an actual payoff that is the same as that which was expected and, therefore, it is not certain that any concessions will be able to be forced. 
The impact of the concessions schedule on the existing payoffs schedule is depicted in Figure 2. The concessions schedule does not immediately add to or subtract from the terrorists' 'wealth' (Note 6). The concessions are associated with risky terrorist actions and those actions must be perpetrated in order for concessions to become a possibility. Because the expected payoffs to all terrorist actions are uncertain and subject to variability, undertaking a higher risk action does not guarantee a particular actual payoff or its associated concession. In the first panel, a concave expected payoffs schedule is sketched. Any positively inclined payoffs schedule that depicts a positive trade-off between risk and reward will suffice. The solid line represents the expected payoffs schedule before the addition of a real or perceived concessions schedule. In the second panel, the concessions schedule from Figure 1 is depicted.

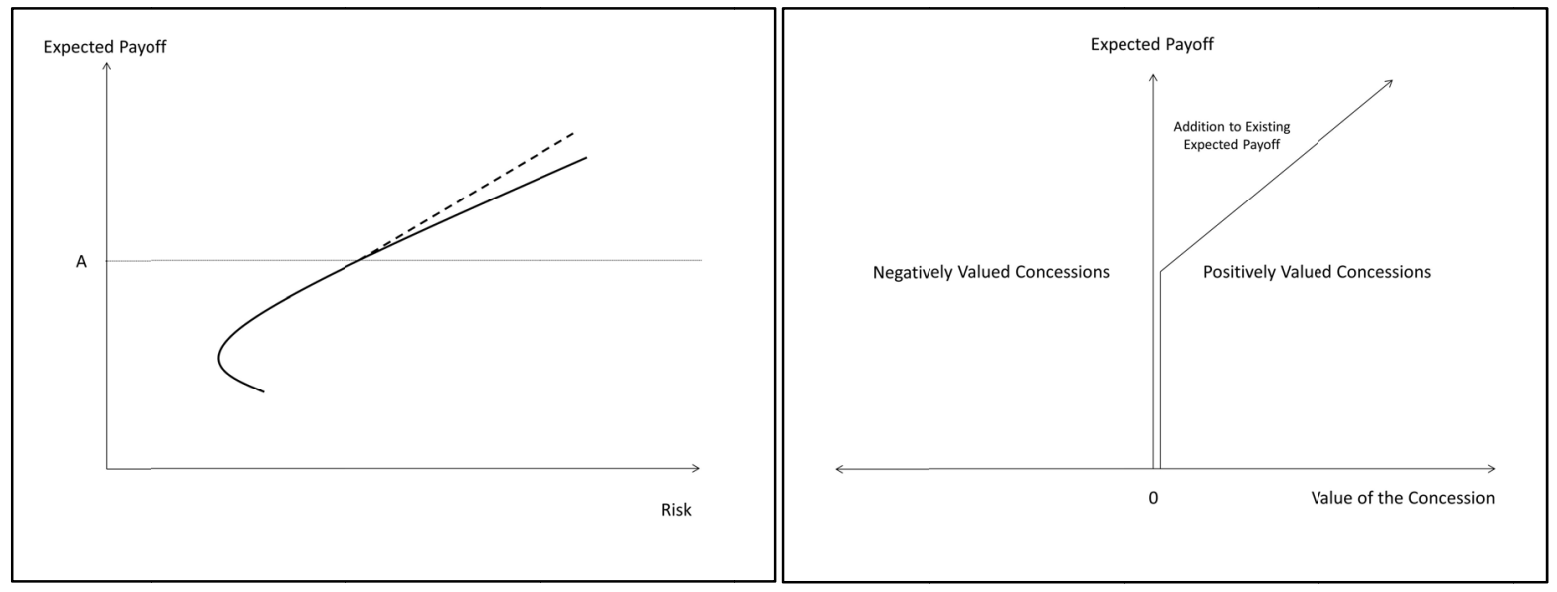

Figure 2. Adding a convex concessions schedule to an existing payoffs schedule

Point A in the first panel corresponds to the point at which the concessions schedule in the second panel 'kinks' and becomes positively valued. Past this point, the existing expected payoffs schedule is altered by the concessions schedule. This alteration is depicted by the dashed line. For terrorist actions with expected payoffs greater than A, expected payoffs are higher per unit of risk than they were before. Conventional wisdom would tell us that this will make the terrorists more risk seeking. The riskier terrorist actions now have higher expected payoffs. If the terrorists take more risks, higher expected payoffs and government concessions are available. However, increasing the expected payoffs to riskier terrorist actions does not necessarily make those actions more desirable. All of the payoffs are risky. Nothing is certain. Higher expected payoffs are characterised by higher levels of risk and a greater chance that the actual outcome - both the payoff and the concession - may diverge significantly from the outcome that was expected. Only if terrorists are made more risk seeking by the presence of this type of concessions schedule will they be enticed to engage in higher risk-higher reward actions.

Now let us consider a 'negative concession' or penalty that increases monotonely in the negative for expected payoffs past some point. Figure 3 contains a negative concessions schedule that is a mirror image of the convex schedule depicted in Figure 1. It attaches increasing penalties to actions that have expected payoffs beyond some point. Figure 3, deliberately stylised though it may be, might be interpreted as attaching new penalties or sanctions to terrorist actions that have an expected payoff past some point (Note 7). It is assumed that existing penalties, such as prison sentences, are already reflected in the existing expected payoffs schedule. The effect of the addition of a negative concessions schedule to the existing payoffs schedule is to reduce the expected payoffs that attend riskier terrorist actions. Intuitively, it might be expected that this would make terrorists less risk seeking and less likely to choose to engage in the more risky terrorist actions that might be found in their opportunity set. Once more, however, it is not necessarily the case that reducing the payoffs to higher risk terrorist actions will be associated with an increase in terrorist risk aversion. Only if terrorists are made more averse to risk or if the structure of the expected payoffs changes such that it becomes optimal to choose a lower risk action will terrorists avoid higher risk terrorist actions as a consequence of adding the negative concessions schedule to the existing payoffs schedule. 


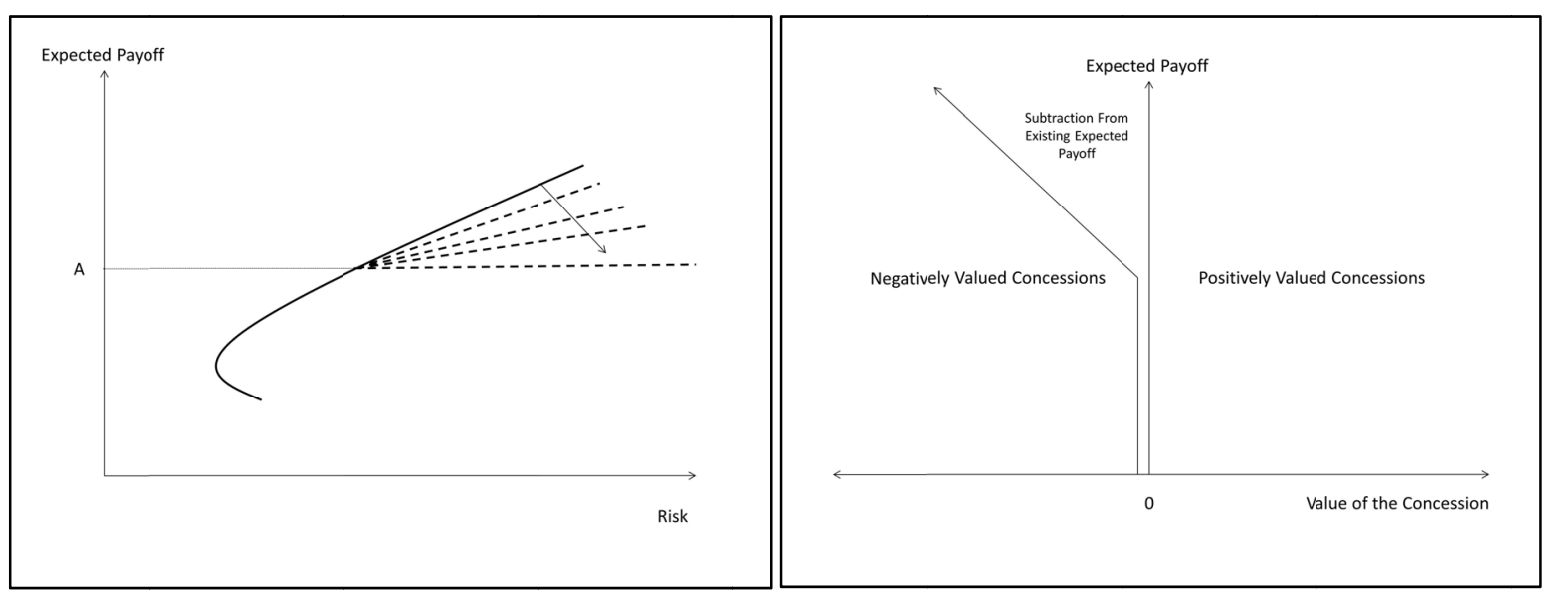

Figure 3. Adding a concave concessions schedule to an existing payoffs schedule

\section{Risky Choices and Concessions Schedules}

Concessions schedules that are not synonymous with an existing payoffs schedule alter or add to that existing payoffs schedule. In the previous section, expected payoffs, risk and concessions were linked together in a manner that allows us to explore situations where the terrorist must bear higher risk to increase his expected payoffs and, in doing so, believes that the government may be forced to yield concessions if the terrorist action does achieve payoffs past some point. The positive or negative concessions that the government applies may offset each other to some degree. The net effects of simultaneously imposed positive and negative concessions are determined by what the terrorist perceives to be the case. The question that we seek to answer is whether adjustments to the existing payoffs schedule by the imposition of either positive or negative concessions make all terrorists more risk seeking or more averse to risk. In the cases that we considered in the previous section, the expected payoffs to more risky terrorist actions were enhanced by the addition of positively valued concessions and then, in the second case, diminished by the addition of negative concessions.

Ross (2004) presents a mathematical theorem and proof (Note 8) that provides a technical response to our question for popular specifications of the individual's absolute risk aversion (Note 9). In most cases, the types of 'additions' that Ross considers from an agency theoretical perspective have market value and represent additions to the wealth of the individual who receives them. The concessions schedules that we are considering have no immediate value to the terrorist. They are unlike, for example, windfall gains of resources. If, within a terrorism context, concessions schedules have no immediate effect on the 'wealth' of the terrorist group, then it is less clear how Ross's second theorem and its fourth corollary will hold and alternative theoretical arguments are needed in order to explain the impact of concessions on terrorists' risk preferences or choices of risky actions. Our results are consistent with Ross's but the arguments through which they are arrived at are more accessible. Adding the positively sloped convex concessions schedule depicted in Figure 2 to the existing payoffs schedule will not convexify all terrorists' utility functions or encourage terrorists to choose a riskier action. This type of concessions schedule will not make terrorists more risk seeking. Now consider the concave concessions schedule depicted in Figure 3. Although it can never convexify a utility function or make the terrorists choose a riskier action, a positively sloped negative concessions schedule will make it rational for the risk-averse terrorist to choose a less risky action. These conclusions are best explained and illustrated by adding the terrorist's indifference curve mappings to the payoffs schedule depicted in Figures 2 and 3.

The first panel of Figure 4 depicts an existing expected payoffs schedule. The terrorist's utility is represented by the indifference curve mapping associated with the relevant utility function. The indifference curves are drawn relatively flat to indicate a low level of risk aversion and are located towards the eastern part of the payoffs schedule to indicate the willingness of a less risk averse terrorist to engage in more risky terrorist actions. The positive concessions add to the existing payoffs schedule. Ross's theoretical work suggests that the positive concessions do not shift the terrorist onto a set of flatter more risk seeking indifference curves located further eastwards along the existing payoffs schedule. Although the terrorist now obtains higher expected payoffs and higher expected utility for the relatively more risky actions he does not necessarily become more risk seeking. The more risky actions do not become more desirable to him as a result of their now-higher expected payoffs and he continues to take no more risk than he did in the absence of the alteration to the payoffs schedule initiated by 
the imposition of the positive concessions schedule. This is indicated by the vertical movement of the utility maximising point from $\mathrm{B}$ to $\mathrm{C}$. It is possible in fact that a positive concessions schedule will alter the expected payoffs schedule in a manner that increases the terrorist's risk aversion and shifts the terrorist westwards onto a 'steeper' more risk-averse indifference curve mapping.

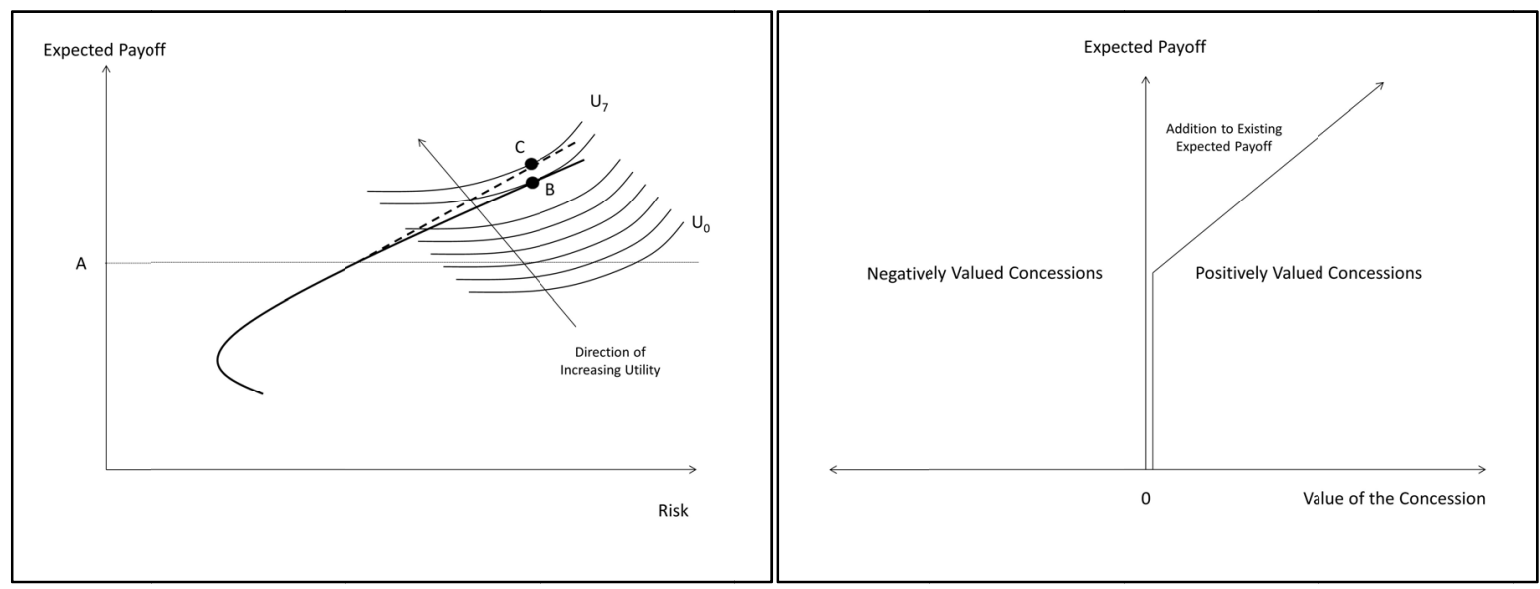

Figure 4. Convex concessions and terrorist preferences for more risky actions

Ross's technical-mathematical approach provides a rigorous explanation for why this may be the case in a scenario where the additions to an existing schedule add to the 'wealth' of the individual receiving them. In the terrorism context, this may not be the case and we must find an alternative logical-economic explanation for why this alteration of the expected payoffs schedule does not entice terrorists to choose riskier actions. Although the concessions schedules will alter the expected payoffs schedule, the addition of a concessions schedule where there was none before may not increase terrorists' 'wealth' or add to the terrorists' accumulated payoffs or resources. In fact, the concessions schedule may have no immediate value to the terrorists. In this case, the best way to explain the impact (or non-impact) of the positive concessions schedule depicted in Figure 2 on the terrorist's risk preferences is as follows. The concessions schedule only interacts with risky expected payoffs. Nothing is certain. Increments to the expected payoffs associated with increasingly risky terrorist actions do not make those riskier terrorist actions more desirable because they do not interact with terrorist risk aversion in a manner that can make the terrorist more risk seeking.

A concessions schedule that increases the expected payoffs of more risky terrorist actions is not an addition to the terrorists' 'wealth' or accumulated payoffs or resources endowment and it is, of course, accumulated payoffs or wealth or resources that are the reference point for both relative and absolute risk aversion. If a terrorist preferred to bear a particular amount of risk before the concessions schedule was applied, he now simply receives a higher expected payoff than before but he is not enticed to bear more risk. The concessions schedule has not made higher risk actions more attractive to terrorists who are more averse to risk. Although the expected payoffs are higher, the terrorist must still bear more risk to obtain higher expected payoffs and a terrorist who is averse to risk will not wish to do so. A careful inspection of Figure 4 reveals that the terrorist might actually choose a less risky action after the concessions are added to the expected payoffs schedule. Where the terrorist preferred the amount of risk associated with point B and the associated expected payoff, after the concessions schedule is imposed the terrorist may switch to a less risky action and obtain the same expected payoff with less risk. That is, rather than moving upwards to point $\mathrm{C}$, the terrorist may be shifted horizontally westwards. If this happens, the terrorist chooses a lower risk action and one that, presumably, has less expected 'impact' than the action associated with the initial choice at point $\mathrm{B}$. This would be a desirable outcome for the government.

Positive concessions that increase expected payoffs do not entice the terrorist to engage in riskier terrorist actions. Let us now explore the case of negative concessions. A schedule of negative concessions or penalties is a concave schedule that reduces the expected payoffs to terrorism. The schedule that we have drawn in Figure 3 is simply the mirror image of the convex schedule in Figure 2. Past some point, this negative concessions schedule acts to completely offset the additional expected payoffs obtained from increasingly risky terrorist actions. This is a very straightforward concessions schedule but our conclusions regarding its effect on terrorist preferences for risk apply to any concave monotonely increasing concessions schedule. In Figure 5 the effect of the concave 
negative concessions schedule is depicted. Again, Ross's technical-mathematical approach provides an explanation for the resulting concavification of the terrorist's utility function under conditions where the negative concessions subtract from the terrorist's 'wealth'. In less technical terms and for situations where there is no immediate subtraction from the terrorist's 'wealth' or resources or accumulated payoffs, the result can be explained as follows. First, one may wonder why the negative concessions might interact with the terrorists' choice of risky actions when the positive concessions do not even when neither represents an addition or subtraction from the terrorists' accumulated payoffs or resources endowments. In the first panel of Figure 5, the terrorist is initially at point B. This is the same point from which the story contained in Figure 4 commenced. The imposition of the negative concessions schedule that is depicted in the second panel of Figure 5 completely offsets the gains in expected payoffs obtained from risky terrorist actions beyond some point. As such, the terrorist finds himself expecting a payoff of $\mathrm{C}$ from the relatively higher risk terrorist action instead of $\mathrm{B}$. The expected payoffs schedule has been effectively truncated. It is now rational for the terrorist to adjust his preferences and move to a lower risk action at point $\mathrm{D}$. At point $\mathrm{D}$, the terrorist expects the same payoff as he would obtain at point $\mathrm{C}$ but it is obtainable with far less risk. The utility maximising behaviour of the terrorist will lead him to choose the less risky, lower payoff action at point D rather than the more risky, equal payoff action at point $\mathrm{C}$. The impact of the negative concessions schedule is much more straightforward and it also coincides with an intuitive assessment of the likely impact of penalties such as those depicted by a concave schedule like the one in the second panel of Figure 5.

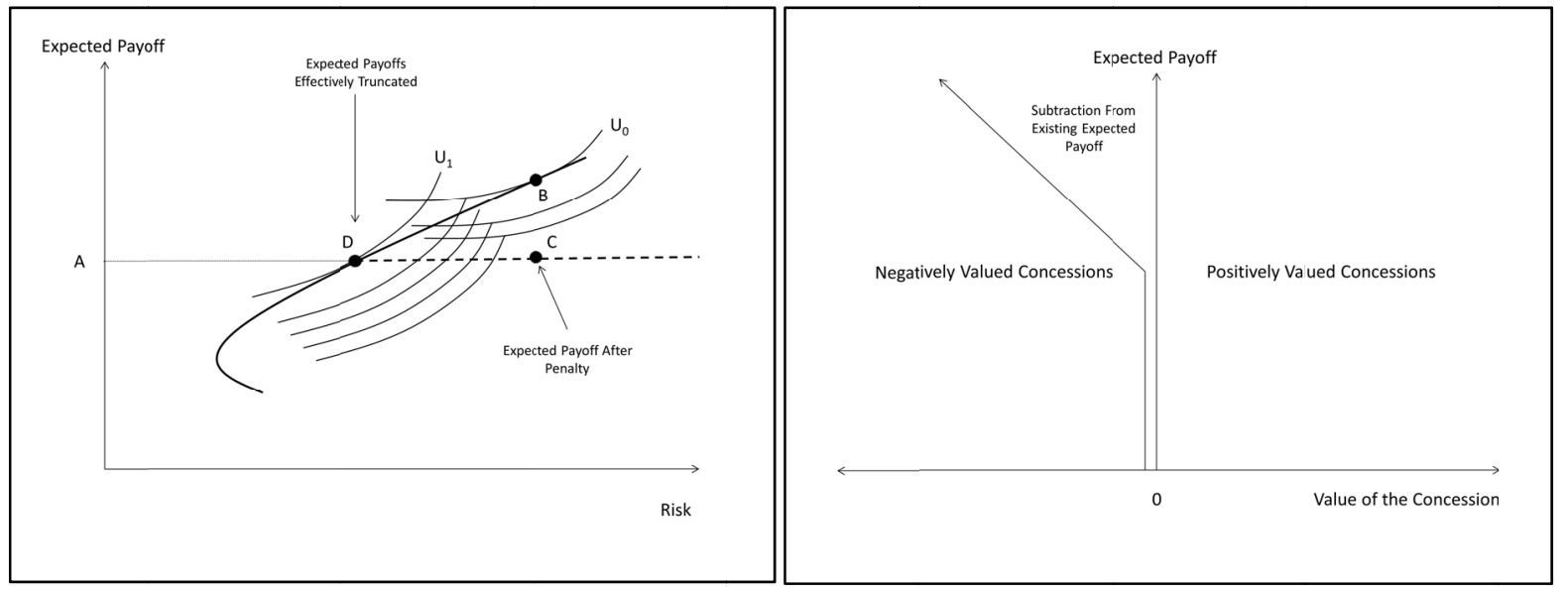

Figure 5. Concave concessions and terrorist preferences for risk

\section{Making Terrorists More Risk Seeking}

If, contrary to conventional intuition, a convex, positive, monotonely increasing concessions schedule that magnifies expected payoffs past some point does not make all terrorists more risk seeking, what type of concessions schedule will make all terrorists more risk seeking? The answer is a convex, positive, monotonely declining concessions schedule (Ross, 2004, p.218). Such a concessions schedule works, broadly speaking, in a manner opposite to our negative concessions schedule. It too 'truncates' the expected payoffs schedule but it does so in such a way as to protect the terrorist from expected payoffs that are below some level whilst leaving the upside potential intact (Ross, 2004). This positive monotonely declining concessions schedule convexifies the terrorist. The reason for this lies in its effect on the expected payoffs schedule. Although the upside remains intact, the terrorist cannot receive a payoff less than A regardless of how much risk he takes. The terrorist now finds the expected payoffs schedule is effectively relocated westwards and more risky actions become desirable given the trade-off now characterising risk and reward. This is depicted in the first panel of Figure 6 . Where the more risk averse terrorist was initially located at point B, the concessions schedule that protects on the downside whilst leaving the upside potential intact 'pulls' everything westwards. The terrorist now chooses a 'more risky' action at point $\mathrm{C}$. By doing so he receives a higher expected payoff but does not bear any 'real' additional risk. The protection on the downside effectively reduces the risk associated with more risky terrorist actions.

It is difficult to imagine that a government or a terrorist group could impose such a concessions schedule, even inadvertently. The only possibility is a situation where a terrorist attaches an inverse valuation to a negative concessions schedule for expected payoffs below some point. If the negative concessions schedule involves, at 
the limit, the death of the terrorist (Note 10) following a failed terrorist action then a positive, convex, monotonely declining concessions schedule may be perceived by the terrorist under some circumstances. Under such circumstances, not surviving the failed action might be positively and increasingly valued as expected payoffs decline past some point if death is perceived by the terrorist as being better than other outcomes such as capture and imprisonment. If death is accorded a 'payoff equivalent' of A, for example, the terrorist's downside is effectively truncated even though, from a point of view other than the terrorist's, the downside appears 'infinite'.

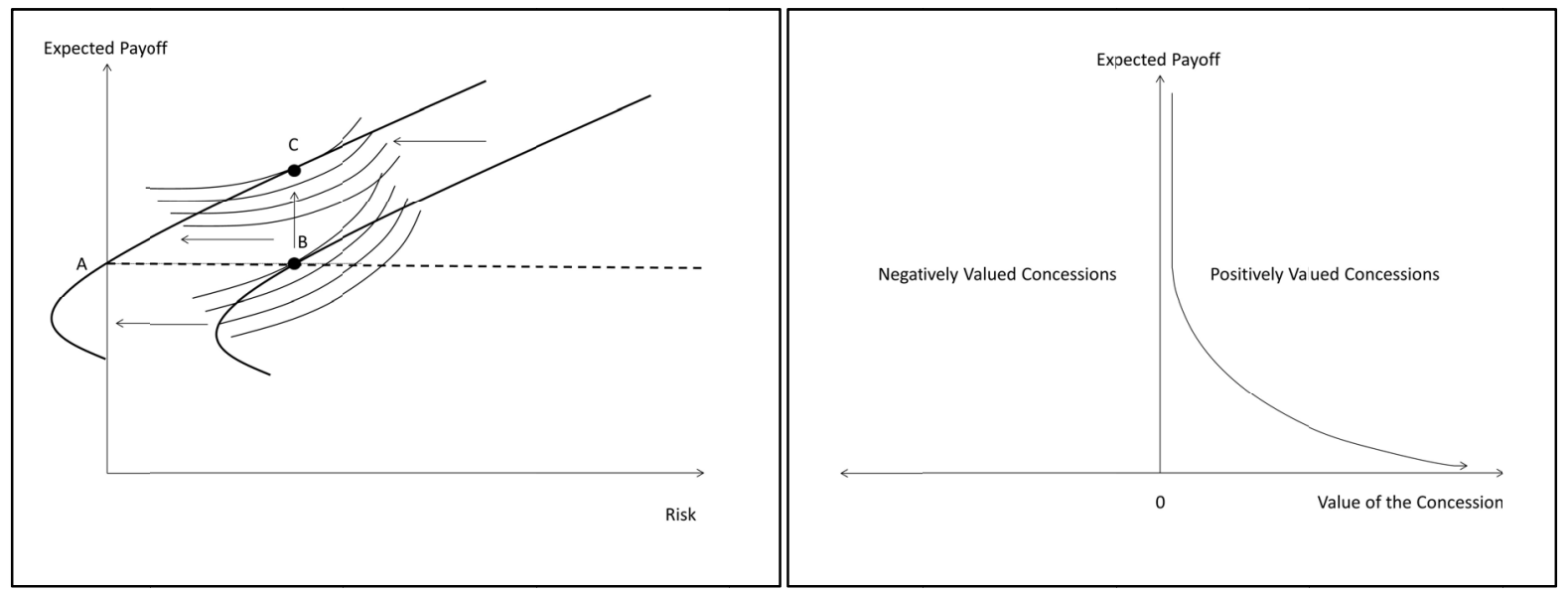

Figure 6. Convex positive declining concessions and terrorist preferences for risk

\section{Expected Payoffs and Innovations in Terrorist Actions}

When negative concessions or penalties are added to an existing expected payoffs schedule, we would expect there to be a reordering of terrorists' preferences. This is clearly the case following the introduction of harsher penalties for skyjacking in the United States in the 1970s (Landes 1978). Despite the introduction of penalties we still observe some terrorists to engage in them just as we see some terrorists engage in actions that have much more variable outcomes than others actions that they could have chosen. Why would any terrorist continue to choose an action at point C, say, in Figure 5 when the expected payoff is the same as a less risky action D once the newly added penalties for the higher expected payoff action are taken into consideration? Why would all terrorists not choose less risky actions with lower expected payoffs and lower negative concessions? There are three potential answers to these questions. First, the terrorist may not choose his actions in a manner that maximises expected utility. Even if he tries to maximise expected utility, the terrorist may make a mistake. Expected utility theory does not rule out erroneous or poor decision-making. Second, the terrorist may be risk seeking rather than risk averse. A risk seeking terrorist will give up expected payoffs in order to take on more risk. This type of terrorist is depicted by the indifference curve mapping in Figure 7. This will explain some but not all acts of terrorism in the face of increasingly harsh penalties. A risk seeking terrorist will allocate all of his resources to the most risky action. This would explain why we might observe actions to the right of point $\mathrm{C}$ in Figure 5, for example.

Innovation is also an important part of the explanation for the types of actions that we observe relative to what we know about the expected payoffs schedule, the risk-reward trade-off that characterises it and the economic theory that attempts to explain terrorists' choices. The expected payoffs schedule, if it is constructed on the basis of the averages of the payoffs obtained from terrorist actions in the past, does not reflect the payoffs available to a new kind of terrorist action until that action is perpetrated at least once. Schumpeterian innovations 'shatter' the existing equilibrium and structures, which must then be reassembled in a manner that includes those innovations and the payoffs associated with them. A terrorist action of a new kind may be located above the existing expected payoffs schedule, providing the terrorist who innovates with an expected payoff that exceeds that which would be commensurable or obtainable at the same level of risk by means of a well-tried terrorist action. It is only after the action is tried for the first time that governments will react with security measures, for example. It is only after the action is tried for the first time that terrorists themselves will be more knowledgeable about the types of payoffs that might be obtainable by means of the innovative action. Until that time, there is no knowledge within the existing expected payoffs schedule that provides an indication of the risk-reward trade-off 
that should be associated with the action. Indeed, the existing expected payoffs schedule does not reflect the risks and rewards of the action at all in any way. It is only through the 'entrepreneurial' actions of the terrorist that the expected payoffs schedule comes to reflect a new trade-off between risk and reward that incorporates the innovation in terrorist action.

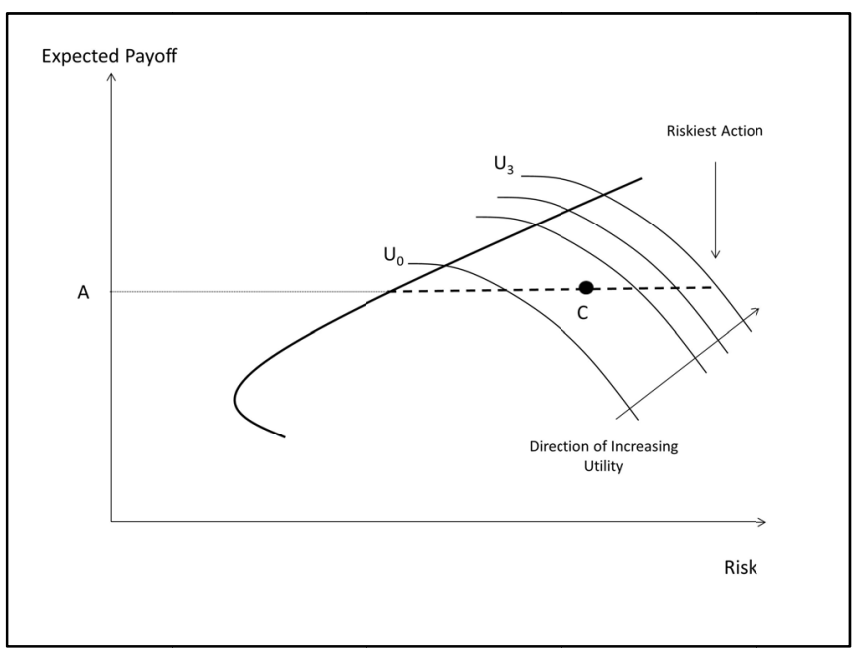

Figure 7. The risk seeking terrorist prefers more risk to less

\section{Discussion, Conclusions and Future Research}

A negative, concave concessions or penalties schedule shifts the utility maximising risk averse terrorist to a lower risk lower reward section of the expected payoffs schedule. A positive, convex concessions schedule does not shift the utility maximising risk averse terrorist to a higher risk higher expected payoff section of the expected payoffs schedule. Although a positive concessions schedule increases the expected payoffs to risky terrorist actions past some point it does not make these risky actions more desirable to all terrorists. The terrorist remains just as risk averse as he was before. Our expected payoffs schedule, indifference curve and concessions schedule geometry depicts the impact of government concessions on the terrorist's expected payoffs and preferences for risk in a manner that has not been presented before in the literature. It allows us to explore the relationship between expected payoffs, risk and concessions in a context where a concessions schedule alters an existing payoffs schedule but does not replace it or become synonymous with it. The results are consistent with the more technical-mathematical approach taken by Ross (2004) but they are more accessible.

Although we have, for the most part, drawn 'stylised' concessions schedules, the results will hold for any other types of concessions schedules with the same properties. That is, convex concessions schedules that are positive and increasing past some point will not make all terrorists more risk seeking. The terrorist will obtain a higher expected utility from the risky actions that he was willing to undertake but he will not be enticed to embark upon riskier actions simply because the expected payoffs are higher. Concave concessions that are negative and increasing past some point will make terrorists behave as though they are more averse to risk. The concave concessions schedule truncates the terrorists' expected payoffs effectively equates the expected payoffs of less risky and more risky actions. The terrorist is now faced with a choice between a less risky action and a more risky action each with the same expected payoff. A risk-averse utility maximiser will choose the less risky action. The only type of concessions schedule that will certainly make the terrorist more risk seeking is the implausible one that leaves the higher expected payoffs to more risky terrorist actions intact whilst providing a 'floor' below which actual payoffs cannot fall. When expected payoffs below some point are ruled out, the terrorist's expected payoffs are reshaped such that higher risk higher expected payoff terrorist actions effectively have the same level of risk as lower risk actions. These results can be extended and the same analytical apparatus can be used for concessions schedules with different shapes. From a government's point of view, the results imply that keeping open the possibility of positively valued concessions attached to terrorist actions that are expected to yield payoffs past some threshold point will not be attended by an increase in the number of terrorists pursuing higher payoffs through more risky terrorist actions. When less risk-averse terrorists do engage in such actions and when 
they are successful at it, the government may use positively valued concessions to alleviate the crisis without making terrorists more risk seeking.

The analytical treatment of concessions within the terrorism studies literature is quite advanced but relevant results can be found in a research program that is ongoing in other parts of economics. Both Ross (2004) and Carpenter (2000) make some progress in identifying the conditions under which a convex schedule will convexify an agent's utility function. The type of problem that Ross and Carpenter address is a part of the research program directed towards the investigation of the principal-agent problem. In turn, parts of this research program fall under the broader research program that investigates the role of incentives in economic decision-making and risk taking (Note 11). This literature has received an additional boost following the financial crisis of 2008 where excessive risk taking and misaligned incentives figured prominently in the analytical post-mortems carried out over the ensuing several years (Note 12). The number of theoretical advances since Ross (2004) has not been substantial and his paper remains among the few to rigorously address the problem of whether convex schedules convexify an agent's utility function (Note 13).

Granting concessions may not be a sub-optimal negotiation strategy but will granting concessions make terrorists more risk seeking? Will granting concessions that increase the expected payoffs to more risky terrorist actions entice terrorists to engage in those actions? We have addressed this question in this paper. Convex positively valued concessions that increase the expected payoffs to risky terrorist actions will not make 'terrorists' as a general category more risk seeking. This result emerges clearly when the concessions schedule is treated as being distinct from the expected payoffs schedule. Existing theoretical work has often focussed on exploring decision-making within scenarios where the concessions that may be received from the government are the terrorists' payoffs. Our treatment, by contrast, sets down an expected payoffs schedule that is altered by the imposition of positive or negative government concessions. Expected payoffs are risky and the actual outcomes of a terrorist action may diverge from those that were expected. Linked as they are in our analysis to the payoffs to risk actions, positive concessions are also risky and uncertain. Although they may increase the expected payoffs to more risky terrorist actions, positive concessions do not represent additions to the terrorists' accumulated payoffs, resources or 'wealth'. The expected payoffs schedule is altered but not in a manner that entices the utility maximising risk averse terrorist to engage in riskier actions.

A research program that explores the relationship between incentives, broadly speaking, and terrorist behaviour may be either mathematical or more logical-theoretical in nature. A mathematical approach would build upon the types of results found in Carpenter (2000), Ross (2004) and Braido and Ferreira (2006). In particular, it would be interesting to prove that the results contained in Ross (2004) apply in situations where a terrorist group dynamically accumulates actual payoffs and concessions over time in a series of terrorist actions. Such an analysis would highlight the relevance of decreasing and increasing absolute risk aversion in the examination of terrorist choices in a dynamic setting. Higher mathematics is not the only pathway that may be followed. Incentives shape terrorists' behaviours in ways that can be explored through logical argument. This paper has pointed out that terrorists' expected payoffs may be altered by the imposition of concessions and this, in turn, may shape terrorists' choices of risky actions. Two important problems that may be approached in a similar manner concern the examination of the interaction between incentives provided within a terrorist group and the choices of terrorists associated with that group and the examination of the effects of attempts by terrorist groups to resource, encourage or incentivise lone individual terrorists (Note 14) who are operating more or less independently in dispersed locations. The use of different methods, some drawn from research in other parts of economics, to explore terrorist behaviour will likely yield some worthwhile results.

\section{References}

Abrahms, M. (2006). Why terrorism does not work. International Security, 31, 42-78. http://dx.doi.org/10.1162/isec.2006.31.2.42

Abrahms, M. (2008). What terrorists really want: terrorist motives and counterterrorism strategy. International Security, 32, 78-105. http://dx.doi.org/10.1162/isec.2008.32.4.78

Abrahms, M. (2011). Does terrorism really work? Evolution in the conventional wisdom since 9/11. Defence and Peace Economics, 22, 583-594. http://dx.doi.org/10.1080/10242694.2011.635954

Braido, L. H. B., \& Ferreira, D. (2006). Options can induce risk taking for arbitrary preferences. Economic Theory, 27, 513-522. http://dx.doi.org/10.1007/s00199-004-0581-6

Butler, C. K. (2007). Prospect theory and coercive bargaining. Journal of Conflict Resolution, 51, 227-250. http://dx.doi.org/10.1177/0022002706297703 
Carpenter, J. N. (2000). Does option compensation increase managerial risk appetite? Journal of Finance, 55, 2311-2331. http://dx.doi.org/10.1111/0022-1082.00288

Coles, J. L., Daniel, N. D., \& Naveen, L. (2006). Managerial incentives and risk taking. Journal of Financial Economics, 79, 431-468. http://dx.doi.org/10.1016/j.jfineco.2004.09.004

Dong, Z., Wang, C., \& Xie, F. (2010). Do executive stock options induce excessive risk taking? Journal of Banking and Finance, 34, 2518-2529. http://dx.doi.org/10.1016/j.jbankfin.2010.04.010

Enders, W., \& Sandler, T. (1993). The effectiveness of anti-terrorism policies: a vector-autoregression-intervention analysis. American Political Science Review, 87, 829-844. http://www.jstor.org/stable/2938817

Enders, W., \& Sandler, T. (2002). Patterns of transnational terrorism, 1970-1999: alternative time-series estimates. International Studies Quarterly, 46, 145-165. http://dx.doi.org/10.1111/1468-2478.00227

Fahlenbruch, R., \& Stulz, R. M. (2011). Bank CEO incentives and the credit crisis. Journal of Financial Economics, 99, 11-26. http://dx.doi.org/10.1016/j.jfineco.2010.08.010

Fearon, J. D. (1995). Rationalist explanations for war. International Organisation, 49, $379-414$. http://dx.doi.org/10.1017/S0020818300033324

Frey, B. S., \& Luechinger, S. (2003). How to fight terrorism: alternatives to deterrence. Defence and Peace Economics, 14, 237-249. http://dx.doi.org/10.1080/1024269032000052923

Graham, J. R., Harvey, C. R., \& Puri, M. (2013). Managerial attitudes and corporate actions. Journal of Financial Economics, 109, 103-121. http://dx.doi.org/10.1016/j.jfineco.2013.01.010

Kahneman, D., \& Tversky, A. (1979). Prospect theory: an analysis of decision under risk. Econometrica, 47, 263-292. http://www.jstor.org/stable/1914185

Landes, W. M. (1978). An economic study of U.S. aircraft hijacking: 1961 to 1976. Journal of Law and Economics, 21, 1-31.

Lapan, H. E., \& Sandler, T. (1988). To bargain or not bargain: that is the question. American Economic Review Papers and Proceedings of the One-Hundredth Annual Meeting of the American Economic Association, 78, 16-21. http://www.jstor.org/stable/1818090

O’Neill, B. (2001). Risk aversion in international relations theory. International Studies Quarterly, 45, 617-640. http://dx.doi.org/10.1111/0020-8833.00217

Panageas, S., \& Westerfield, M. M. (2009). High-water marks: high risk appetites? Convex compensation, long horizons and portfolio choice. Journal of Finance, 64, 1-36. http://dx.doi.org/10.1111/j.1540-6261.2008.01427.x

Phillips, P. J. (2009). Applying portfolio theory to the analysis of terrorism: computing the set of attack method combinations from which the rational terrorist group will choose in order to maximise injuries and fatalities. Defence and Peace Economics, 20, 193-213. http://dx.doi.org/10.1080/10242690801923124

Powell, R. (2002). Bargaining theory and international conflict. Annual Review of Political Science, 5, 1-30. http://dx.doi.org/10.1146/annurev.polisci.5.092601.141138

Pratt, J. W. (1964). Risk aversion in the small and in the large. Econometrica, 32, $122-136$. http://www.jstor.org/stable/1913738

Ross, S. A. (2004). Compensation, incentives and the duality of risk aversion and riskiness. Journal of Finance, 59, 207-225. http://dx.doi.org/10.1111/j.1540-6261.2004.00631.x.

Rubinstein, A. (1982). Perfect equilibrium in a bargaining model. Econometrica, 50, 97-110. http://www.jstor.org/stable/1912531

Sandler, T., Tschirhart, J. T., \& Cauley, J. (1983). A theoretical analysis of transnational terrorism. American Political Science Review, 77, 36-54. http://www.jstor.org/stable/1956010

Siqueira, K., \& Sandler, T. (2006). Terrorists versus the government: strategic interaction, support, sponsorship. Journal of Conflict Resolution, 50, 878-898. http://dx.doi.org/10.1177/0022002706293469

Skaperdas, S. (2006). Bargaining versus fighting. Defence and Peace Economics, 17, $657-676$. http://dx.doi.org/10.1080/10242690601025617 
Tchistyi, A., Yermack, D., \& Yun, H. (2011). Negative hedging: performance-sensitive debt and CEO's equity incentives. Journal of Financial and Quantitative Analysis, 46, $657-686$. http://dx.doi.org/10.1017/S0022109011000068

Tversky, A., \& Kahneman, D. (1992). Advances in prospect theory: cumulative representation of uncertainty. Journal of Risk and Uncertainty, 5, 297-323. http://dx.doi.org/10.1007/BF00122574

Windram, R. (2005). Risk-taking incentives: a review of the literature. Journal of Economic Surveys, 19 , 65-90. http://dx.doi.org/10.1111/j.0950-0804.2005.00239.x

Winkler, W. (2008). Die Geschichte der RAF. Rororo.

\section{Notes}

Note 1. Peter Lorenz-prisoner of the Movement 2 June.

Note 2. Also see Landes (1978), Enders and Sandler (1993), Enders and Sandler (2002), Frey and Luechinger (2003) and Siqueira and Sandler (2006).

Note 3. O'Neill's (2001) discussion of the treatment of risk aversion within international relations theory contributes the background to this discussion.

Note 4. The 'conventional wisdom' might be interpreted as follows: governments should not negotiate with terrorists because doing so will encourage terrorism. Lapan and Sandler (1988) looked into the optimality of a 'never negotiate' strategy but did not address what seems to be another aspect of the conventional wisdom. That is, granting the terrorists some concessions emboldens them. This could be taken to mean that it encourages more risk seeking.

Note 5. An economist's approach might be to use monetary equivalents (Enders and Sandler 2002).

Note 6. 'Wealth' is the accumulated payoffs of the terrorist or terrorist group or the terrorist or terrorist group's resources. It might have a monetary equivalent or it might not. The terrorists' 'wealth' is assumed to interact with the terrorists' relative and absolute risk aversion in the same sense that monetary wealth interacts with an economic agent's risk aversion in more orthodox settings.

Note 7. For example, in the 1960s and 1970s, much stricter prison sentences were imposed for aircraft 'skyjacking' after a spate of incidences (see Landes 1978). This can be analysed as negative additions to the existing expected payoffs schedule.

Note 8. See Ross's second theorem and its fourth corollary (p.216-217).

Note 9. An individual's utility is described by both relative and absolute risk aversion (see Pratt 1964). Different specifications of the utility function (power, exponential, logarithmic and quadratic) are characterised by different types of relative and absolute risk aversion. A popular specification is 'decreasing absolute risk aversion' (DARA). Individuals with decreasing absolute risk aversion allocate more resources to risky actions as payoffs accumulate.

Note 10. This is a government's negative concessions or penalties schedule. In this case, relevant causes of death do not include the terrorist's suicide.

Note 11. See the review by Windram (2005).

Note 12. For example, see Fahlenbrach and Stulz (2011).

Note 13. See Braido and Ferreira (2006), Coles, Daniel and Naveen (2006), Panageas and Westerfield (2009), Dong, Wang and Xie (2010), Tchistyi, Yermack and Yun (2011) and Graham, Harvey and Puri (2013).

Note 14. These could be thought of as 'quasi' lone wolves. A true lone wolf terrorist operates alone.

\section{Copyrights}

Copyright for this article is retained by the author(s), with first publication rights granted to the journal.

This is an open-access article distributed under the terms and conditions of the Creative Commons Attribution license (http://creativecommons.org/licenses/by/3.0/). 